Int. J. Dev. Biol. 61: 689-696 (2017)

doi: $10.1387 / \mathrm{ijdb} .170219$ is

\title{
Amphioxus regeneration: evolutionary and biomedical implications
}

\author{
ILDIKÓ M.L. SOMORJAI ${ }^{* 1,2}$ \\ ${ }^{1}$ Biomedical Sciences Research Complex, North Haugh and \\ ${ }^{2}$ Scottish Oceans Institute, East Sands, University of St Andrews, St Andrews, Scotland, UK
}

\begin{abstract}
Regeneration is a variable trait in chordates, with some species capable of impressive abilities, and others of only wound healing with scarring. Regenerative capacity has been reported in the literature for 5 species from two cephalochordate genera, Branchiostoma and Asymmetron. Its cellular and molecular bases have been studied in some detail in only two species: tail regeneration in the European amphioxus B. lanceolatum; and oral cirrus regeneration in the Asian species $B$. japonicum. Gene expression analyses of germline formation and posterior elongation in cephalochordate embryos provide some insight into regulation of progenitor and stem cell function. When combined with functional studies of gene function, including overexpression and knockdown, these will open the door to amphioxus as a good model not only for understanding the evolution of regeneration, but also for biomedical purposes.
\end{abstract}

KEY WORDS: amphioxus, cephalochordate, regeneration, chordate, stem cell

\section{Preamble}

When I first began to search for literature describing cephalochordate regeneration a decade ago, I came across Asexual propagation and regeneration (1960), by Vorontsova and Liosner. Chapter XVII was devoted to reparative regeneration in the Echinodermata and the Lower Chordata. On page 283, under the heading "Acrania", they wrote:

"There are only a few studies devoted to regeneration in amphioxus. Biberhoffer(sic) (1906) discovered regenerative phenomena in the most anterior parts of amphioxus containing portions of the notochord (Fig. 149). Regeneration of the posterior part of the body is doubtful (Probst, 1930)".

The latter is accompanied by a line drawing, reproduced from Biberhofer (1906) showing at best limited regeneration of the anterior end of an amphioxus. This is a faithful account of the poverty of research into amphioxus regeneration until the end of the $20^{\text {th }}$ century.

Following a brief introduction to the deuterostome regeneration context, I review here the literature on cephalochordate regeneration, as well as recent advances that have informed us on how amphioxus regeneration fits into the wider picture of chordate regeneration and stem cell biology.

\section{The chordate regeneration context}

Most organisms are subject to injuries at some stage of their lives that require a physiological and cellular response in order to ensure survival. This can range from daily wear-and-tear associated with normal ageing and cellular turnover, to traumatic events such as amputation. While wound healing and tissue replacement are common, the regrowth of lost body parts has a real energetic cost. The ability to regenerate as a trait is therefore extremely variable in the animal kingdom both in terms of frequency as well as penetrance, depending both on the ontogenetic stage of the organism as well as on the damaged tissue (Bely and Nyberg 2010; Seifert and Voss 2013).

Deuterostomes, which include ambulacrarians (echinoderms + hemichordates) and chordates (Fig. 1), are a good example of the regenerative spectrum. Asteroid echinoderms such as brittlestars can regenerate an entirely new organism from a discarded arm; in contrast, sea urchins have more limited abilities as adults, but

\footnotetext{
Abbreviations used in this paper: BMP, bone morphogenetic protein, dpa, days postamputation, FGF, fibroblast growth factor, PGC, primordial germ cell, PSC, posterior stem cell, RTK, receptor tyrosine kinase, Wnt, Wingless/Int.
}

\footnotetext{
*Address correspondence to: Ildikó M.L. Somorjai. Biomedical Sciences Research Complex, North Haugh, University of St Andrews, St Andrews, KY169ST, Scotland, UK. e-mail: imls@st-andrews.ac.uk -Tel: +44 (0)133 446 3628. Fax: +44 (0)133 4462595 - web: http://www.st-andrews.ac.uk/profile/imls (iD) http://orcid.org/0000-0001-5243-6664
} 
regenerate well as larvae (reviewed in Carnevali 2006). The hemichordate Ptychodera flava is also emerging as a good system in which to study axial regenerative processes (Luttrell et al., 2016). A similar diversity in regenerative ability is apparent in the chordate lineages (Fig. 1). At one extreme, regeneration of the whole body from small pieces or circulating cells can be achieved, as seen in some colonial ascidians (Voskoboynik et al., 2008). This may be attributable to their use of asexual budding as their primary reproductive strategy (Kürn et al., 2011). Solitary ascidians also regenerate, but comparatively less well (Jeffery 2015). At the other end of the spectrum, many birds and mammals regenerate poorly as adults. For instance, laboratory mice can regenerate their digit tips, but only providing the amputation occurs within the nail bed (Lehoczky et al., 2011) in a process that relies on resident stem cells (Rinkevich et al., 2011). Many salamanders on the other hand can regenerate their limbs, tails, eyes and even jaws (e.g. Henry and Tsonis 2010; Haas and Whited 2017), reflecting the generally high regenerative capacities of anamniotes.

The existence of poor regenerators alongside sometimes closely-related species with more extensive regenerative capacity suggests that as a trait, regeneration may be under selection. For instance, African spiny mice of the Acomys genus are capable of true epimorphic tissue regeneration of ear hole pinnae, an ability lacking in standard laboratory mice (Gawriluk et al., 2016). The predator escape behaviour of skin shedding in spiny mice is thought to be a true case of mammalian autotomy resulting from structural adaptations that favour ease of tissue tearing and healing over scarring (Seifert et al., 2012). Similar proximate causes may explain why zebrafish can regenerate fins but not the tail proper (Gemberling et al., 2013), whereas many gymnotiform electric fish can replace the entire tail, including spinal cord and electroreceptors (Unguez et al., 2013).

At a deeper level, comparison of appendage regeneration in lungfish and salamanders suggests that the cellular and molecular mechanisms for appendage regeneration evolved in sarcopterygians (Nogueira et al., 2016). Combined with the observation that endochondral elements regenerate in Polypterus, an Actinopterygian fish, following pectoral fin amputation, this might indicate that regenerative abilities shared by living vertebrate groups arose at the base of bony fish. However, it is also argued that regeneration has evolved de novo in many lineages, particularly in relation to vertebrate appendages (Brockes and Kumar 2008; Slack 2017), underscoring the complexity of the problem.

In order to address the question of whether regenerative ability is ancestral, or rather independently derived, a good comparative framework assessing homologous structures is needed. Given that urochordates are morphologically, developmentally and genomically derived relative to vertebrates, cephalochordates (commonly referred to as "amphioxus" or "lancelets") represent the best system in which to assess the presence of any shared regenerative mechanisms that might have existed in the chordate ancestor (Fig. $1 \mathrm{~A}, \mathrm{~B})$. In particular, if true limbs are only shared among tetrapods,
A

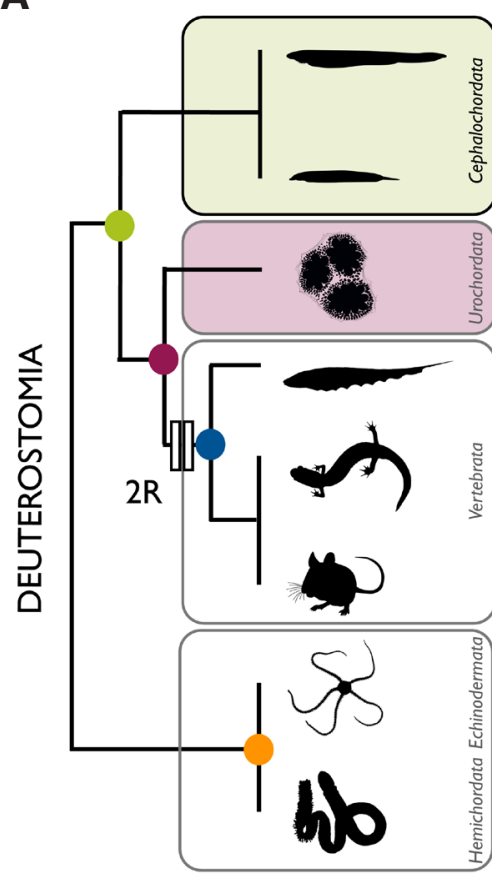

NODES
B

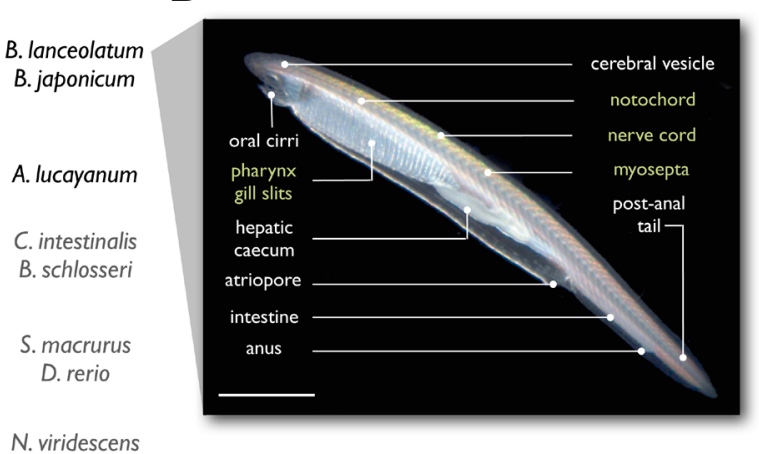

C

\section{A. kempi}

A. percivali

A. filiformis

H. glaberrima

P. flava

B. simodensis

\begin{tabular}{|c|c|c|c|}
\hline \multirow{2}{*}{$\begin{array}{l}\text { Amphioxus } \\
\text { species }\end{array}$} & Regen & Resources & \multirow{2}{*}{$\begin{array}{l}\text { Selected } \\
\text { sources }\end{array}$} \\
\hline & $\begin{array}{ll}A & P \\
\end{array}$ & $\begin{array}{lll}G & T & F\end{array}$ & \\
\hline B.platae & $?$ & & 1,2 \\
\hline B.belcheri & ? & & $3,12-15$ \\
\hline B.japonicum & & & $3,4,15$ \\
\hline B.lanceolatum & & & $5-10,14,16$ \\
\hline B.floridae & & & 15,17 \\
\hline E.maldivensis & & & 18 \\
\hline A. lucayanum & $?$ & & $11,19-20$ \\
\hline
\end{tabular}

Fig. 1. Cephalochordates in the deuterostome regeneration context. (A) Simplified deuterostome phylogeny. Invertebrate chordate lineages are boxed in green (cephalochordates) and pink (urochordates). Representative regenerating taxa are listed to the right next to their clade, including several amphioxus species discussed in this review. The two whole genome duplications (2R) that occurred at the base of vertebrates are indicated by double bars. (B). Anatomy of a young adult amphioxus (Branchiostoma lanceolatum). Key chordate characters are shown in green. Scale, $500 \mu \mathrm{m}$. (C). Table summarising regenerative capacity of amphioxus species (A: anterior; $P$ : posterior), and resources available for each species (G: published sequenced genome; T: transcriptomic/EST data; F: functional tools). The green ticks with an " $m$ " indicate molecular data are available supporting these regeneration studies.

The diamonds are coloured according to the quality of data available (red, few or none; orange, moderate; blue; good). In the case of B. lanceolatum and A. lucayanum, genomes have been sequenced but are not publically available yet. Selected supporting references are provided (full citations in the bibliography): 1. Silva et al., 1995; 2. Silva et al., 1998; 3. Zhang et al., 2009; 4. Kaneto \& Wada 2011; 5. Bert 1867; 6. Probst 1930; 7, Biberhofer 1906; 8. Somorjai et al., 2012a; 9. Somorjai et al., 2012b; 10. Dailey 2017; 11. Andrews 1893; 12. Huang et al., 2014; 13. Feng et al., 2014; 14. Kozmikova \& Kozmik 2015; 15. Wang et al., 2012; 16. Oulion et al., 2012; 17. Putnam et al., 2008; 18 Igawa et al., 2017, 19. Yue et al., 2014; 20. Yue et al., 2016. 
the post-anal tail in contrast is particularly suited for comparative studies of complex regeneration between vertebrates and amphioxus. It consists of several defining chordate characters, including notochord, a dorsal hollow nerve cord and segmented musculature (Fig. 1B). In addition, lancelets diverged prior to the two whole duplication events characteristic of vertebrates (Fig. 1A, "2R"), and have remarkably well conserved gene order (Putnam et al., 2008). The availability of genomic and transcriptomic resources for a number of species, coupled with the ability to perform functional studies in embryos (reviewed in Kozmikova and Kozmik 2015; Fig. $1 \mathrm{C}$ and associated references), set the stage for a new molecular era in cephalochordate regeneration studies.

\section{Regenerative ability in cephalochordates}

The first studies of regeneration in cephalochordates assessed regenerative ability primarily in the European species, Branchiostoma lanceolatum (Bert 1867; Nusbaum 1905; Biberhofer 1906; Probst 1930). Bert (1867) and then Nusbaum (1905) considered this species devoid of regenerative ability, stating that amputation of the tail resulted in the wound taking on a rosy colour (presumably the "red disease"), followed by gradual disintegration of the animal (Bert 1867). Franz (1925) observed that two amphioxus bisected through the atrium upon collection healed, but had not regenerated 8 weeks post-trauma. Neither Biberhofer (1906), nor Probst (1930) had much better luck with adult animals; young juveniles (6-9mm) showed some caudal regeneration after 13 days, but died within three weeks (Probst 1930).

The broadly negative reports in Branchiostoma around the turn of the 20th century contrast with Andrews' (1893) observations of Asymmetron lucayanum when he first described the species. He documents the caudal regenerative ability in this species, indicating a full recovery of all structures including the notochord and nerve cord (Andrews 1893). Direct or indirect evidence of posterior regeneration in Branchiostoma has also been shown in recent years in B. lanceolatum (Bone 1992; Pegeta 1992; Somorjai et al., 2012a), B. platae (Silva et al., 1998), B. japonicum (previously conflated with B. belcheri) and B. belcheri (Zhang et al., 2009). Zhang and colleagues (2009) use posterior blastemas in lieu of embryos to successfully make metaphase spreads for chromosome counts, but otherwise do not discuss regeneration in these species. In contrast, the recent, more detailed analyses of $B$. lanceolatum show that it has considerable tail regeneration capacity (Bone 1992; Pegeta 1992; Somorjai et al., 2012a), even after multiple rounds of amputation (Somorjai et al., 2012b). Interestingly, Bone (1992) states that animals allowed to bury in the gravel or maintained in the dark do not regenerate, in stark contrast to the successful regenerates observed by Pegeta (1992) and Somorjai et al., 2012a, b) under the aforementioned conditions. Together, the studies of caudal regeneration highlight anterior-posterior site of amputation, age, size, nutritional and disease status as important factors in the success and speed of the regenerative response.

Anterior regeneration is less well studied (Fig. 1C), but appears to be much more limited. Of the small $B$. lanceolatum (2.3 $\mathrm{cm}$ ) amputated anteriorly, wound healing was observed in only a single small adult lancelet, and none at all in larger $(2.8 \mathrm{~cm})$ animals (Biberhofer 1906). Recent work confirms that only extreme anterior axial amputations result in any appreciable regeneration, even under prime conditions that promote complete tail regenera- tion (Somorjai et al., 2012a), suggesting this is not an artefact of environmental or physiological conditions. Exceptions to this are the oral cirri, the non-mineralised skeletal rods surrounding the mouth opening, which regenerate well in both $B$. japonicum and B. lanceolatum (Kaneto and Wada 2011; Somorjai et al., 2012a). Data are lacking on anterior regeneration outside Branchiostoma, and no regenerative abilities have been reported for the third cephalochordate genus, Epigonichthys. Thus, of the approximately 30 currently recognised species of cephalochordate (Poss and Boschung 1996), adult regenerative ability has so far been reported in 5 species from two genera, although comparative data indicate that $B$. floridae regenerates similarly well to $B$. lanceolatum (Somorjai, manuscript in preparation). Taken together, these studies suggest that the cephalochordate ancestor would have been able to regenerate the post-anal tail to a respectable degree, but most likely had limited anterior regeneration capacity.

\section{The regenerative process}

\section{Tail regeneration}

The cellular events occurring during regeneration have been described in most detail during post-anal tail regeneration in the European species, B. lanceolatum (Somorjai et al., 2012a). After posterior amputation, humoral fluids are released, and cellular debris around the amputation plane, including fragments of transected muscle fibres, are sloughed away (stage 0). Wound healing immediately follows (stage 1), with epidermal cells closing over the stump. This is occasionally accompanied by formation of haematoma-like swelling, which normally regresses. The timing of these events is variable, taking 1-2 days in adult animals in a size- and age-dependent manner (Somorjai et al., 2012a). In $B$. platae, wounds caused by sectioning the posterior third of the animal healed within 12h (Silva et al., 1995), and necrotic muscle cells were observed beneath the newly formed epithelium. However, the authors report that this was not accompanied by phagocytosis, although elongated endothelial-like cells appeared within two weeks, embedded in connective tissue around an implanted silk thread (Silva et al., 1995).

In the second phase (stage 2), a clear bud or "blastema" forms, a process that takes approximately two weeks, and a predictive cellular bulge may be evident already after one week (Somorjai et al., 2012a). Using EM, Silva and colleagues (1998) report that during posterior regeneration in B. platae, the basal lamina under the bud is interrupted, and endothelial-like cells rest directly on a bed of disorganised collagen fibres. In B. lanceolatum, by 14 days post-amputation (dpa), the posterior tip of the nerve cord exhibits a swelling contiguous with the expanded lumen of the regenerating ependymal tube. Transverse muscle fibres, easily identified by F-Actin staining, are clearly dissociated from the damaged myosepta and the notochord begins to lose its characteristic "stack of coins" organisation, leaving a large space filled with amorphous cellular material anterior to the amputation plane. The notochord blastema in contrast is densely filled with cells (Somorjai et al., 2012a; Fig. 2A).

Within 3 weeks, the tail has begun its outgrowth and the nerve cord can clearly be seen to elongate, maintaining its ependymal tube shape and swollen terminal ampulla (stage 3; Fig. 3C). It has the undifferentiated appearance of the caudal nerve cord in unamputated adults, and lacks anatomically definable photoreceptors 
(Somorjai et al., 2012a). The notochord also extends in line with the nerve cord dorsally; some of the vacuole has been filled with new cells. No new muscle fibres are apparent.

Finally, at stage 4, which can begin any time after approximately one month, overt differentiation begins. The tail continues to elongate, but more slowly; small pigment spots can be seen to populate the nerve cord, suggesting photoreceptor differentiation (or precursor migration), and the notochord cells clearly begin to reorganise and converge (Somorjai et al., 2012a). Cells, likely mesodermal, differentiate into new muscle fibres over the next few months, and myosepta can clearly be seen by eye as birefrigent under polarised light (Somorjai et al., 2012a). The exact details of muscle differentiation are unknown, but the final tail, although sometimes smaller than the original, contains differentiated muscle fibres and responds to external stimuli (Fig. 2D and not shown).

The timing of these events may differ among species, or due to inconsistencies in experimental design across studies. Indeed, the amputation plane itself is important, with regeneration occurring more rapidly closer to the anus than to the tip (Somorjai et al., $2012 a, b)$. A similar phenomenon has been reported in salamanders, where the rate of regenerative outgrowth was positively correlated with tail width at the amputation plane (Voss et al., 2013). However, the observation that repeated amputation of the post-anal tail just anterior to the original cut results in enhanced regeneration speed (Somorjai et al., 2012b), but that amputations anterior to the anus progressively result in poorer regenerative responses (Somorjai et al., 2012a), in spite of similar surface areas, suggest that a number of variables must be involved. The age of the animal, which can be roughly inferred in wild animals based on known population demographics, nevertheless has clear effects on regenerate quality (Somorjai et al., 2012a), and is another important factor that requires further study.

\section{Cirrus regeneration}

During anterior regeneration of the oral cirri in $B$. japonicum, a first phase of wound healing lasting approximately 1 day was reported (stage 1, Kaneto and Wada 2011) in which epidermal cells covered the amputation plane. During stage 2 , cells accumulate at the tip of the regenerating cirri under the new wound epidermis over the course of several days. These are reported to be mesenchymal (Kaneto and Wada 2011) although their origins are difficult to elucidate using cellular morphology alone. Finally, the skeletal rods elongate in stage 3 , a process that normally initiates within 1 week of amputation. The cells within appear somewhat disorganised relative to those more proximal to the amputation plane or distally in unamputated cirri (Kaneto and Wada 2011). The variation in regeneration seen in $B$. japonicum may reflect time spent without food, or exact location of amputation plane. However, it may also reflect age, a factor that was not reported in this study. Small adult $B$. lanceolatumare also able to regenerate cirri, and while not studied in cellular detail, these look grossly normal (Somorjai et al., 2012a), but might eventually develop similar polarity defects to those we have observed in regenerating notochords of ageing animals (Somorjai et al., 2012a). Detailed histology on sections, and in a larger number of animals at precise regeneration stages will be instrumental in assessing the cellular composition and contributions to cirrus regeneration.

\section{Molecular basis of regeneration}

\section{Tail regeneration}

Two studies have addressed the molecular basis of posterior regeneration in amphioxus, primarily using immunohistochemistry and candidate gene expression analysis (Somorjai et al., 2012a,b). Members of the developmental signalling pathways Wnt and BMP are expressed in $B$. lanceolatum in domains consistent with roles in specification and patterning of the blastema. First, Wnt5 is expressed throughout the blastema in cells that are also enriched for $\beta$-catenin protein at the membranes (Somorjai et al., 2012b). The absence of $\beta$-catenin in the nucleus either suggests that Wnt plays a role in modulating adhesion of blastema cells at this stage, or that the nuclear $\beta$-catenin antibody epitope is masked. Second, the stage 2 blastema expresses $m s x$, a downstream target of BMP often expressed in other regenerating systems (Somorjai et al., 2012a). During the elongation phase, the BMP antagonist
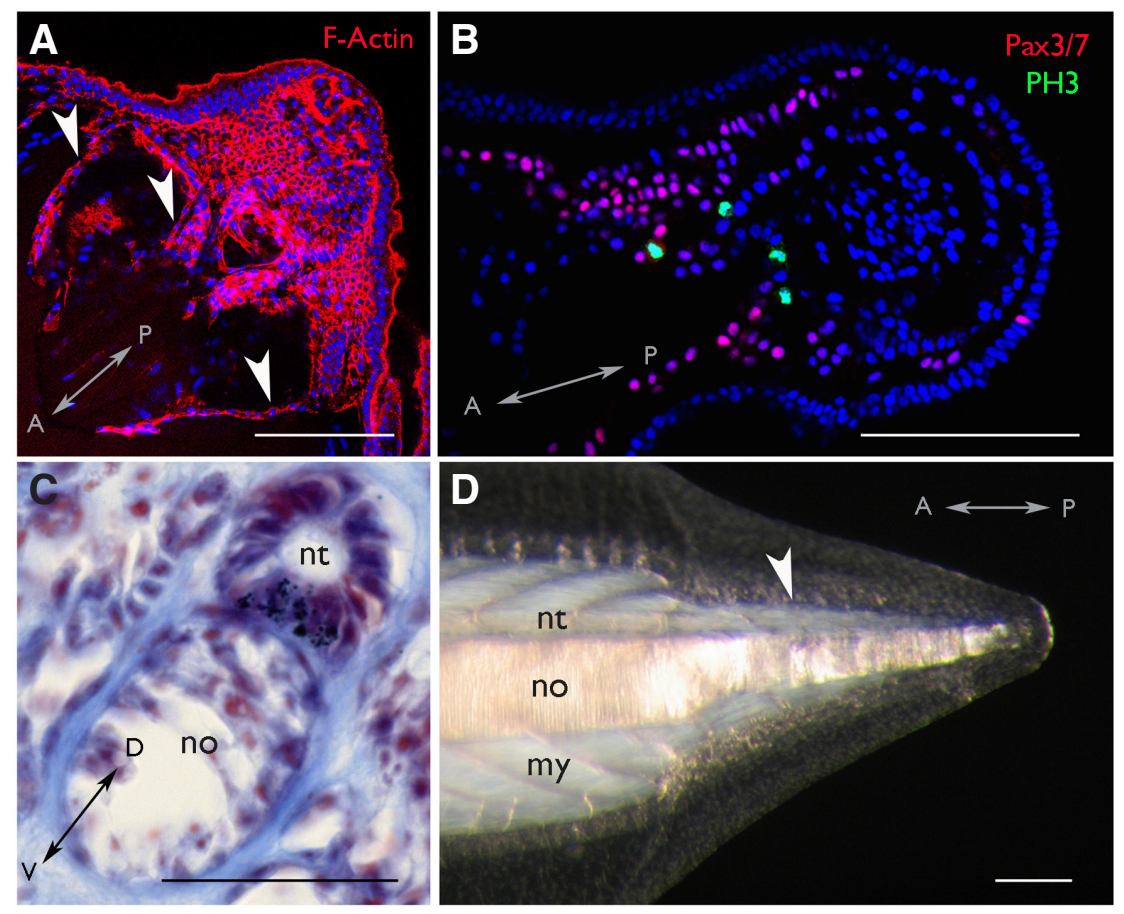

Fig. 2. Tail regeneration in adult $\boldsymbol{B}$. Ianceolatum. (A). Blastema tail bud viewed by confocal microscopy (stage 2). F-Actin staining (red) using Phalloidin demarcates cellular membranes. White arrowheads indicate myoseptal boundaries(B). Elongating regenerate (stage 3) viewed by confocal microscopy. Pax3/7+ and dividing phospho-histone $3(\mathrm{PH} 3+)$ cell populations are shown in red and green, respectively. DAPI labelled nuclei are false-coloured in blue. (C). Transverse section through regenerating tail stained with Mallory trichrome (nuclei, red; connective tissue, blue). The black speckles in the floor of the neural tube are pigment granules normally associated with photoreceptors. (D). Mature regenerate viewed under polarising light (15 weeks post-amputation; stage 4). Differentiated notochord cells are birefringent, and new muscle fibres can clearly be distinguished (white arrowhead). The Anterior-Posterior (A-P) and Dorso-Ventral (D-V) axes are indicated in each panel. nt: nerve cord; no: notochord; my: myosepta. Scale, $100 \mu \mathrm{m}$. 
chordin is expressed in new notochord cells, suggesting a role in differentiation. The neural differentiation marker soxB2, the orthologue of vertebrate sox 17/21, is also expressed in the regenerating ependymal tube (Somorjai et al., 2012a).

Athird study has recently taken a global look at tail regeneration by analysing transcriptomes of the blastema and the unamputated tail (Dailey 2017). As expected, all previously identified players using the candidate approach were recovered (Dailey 2017). A large number of additional genes were also identified from the Wnt, BMP, Notch, FGF and RTK signalling pathways, as well as epimorphic process in amphioxus, as blastema cells show considerable proliferation by phospho-histone $\mathrm{H} 3$ immunostaining, as does the extending nerve cord (Somorjai et al., 2012a; Fig. 2B). The latter further demonstrates that the nerve cord undergoes active neurogenesis during regeneration. Interestingly the extent of this proliferative activity is significantly lower in older animals, and may account for their reduced capacity to regenerate a complete tail. In contrast to tail regeneration, Kaneto and Wada (2011) report that regeneration of the oral cirri occurs via tissue remodelling, as no increase in proliferation was observed. However, it cannot germline and pluripotency factors (Dailey 2017; see below), many of which have neither been characterised during normal development nor regeneration. However, one of the identified blastema transcripts, $S p 5$, is expressed in the amphioxus posterior growth zone and is a target of Wnt $/ \beta$ catenin signalling (Dailey et al., in press). Greater sequencing depth using Illumina in more replicates and at additional regeneration stages are currently underway (Dailey and Somorjai, unpublished). Nevertheless, this initial pilot study has opened up new avenues for understanding the molecular basis of tail regeneration in amphioxus, and provides a comparative framework for identifying processes shared with both ambulacrarians and vertebrates.

\section{Cirrus regeneration}

Oral cirrus regeneration has been used as a model for understanding the evolution of skeletogenesis (Kaneto and Wada 2011). Markers for a number of genes implicated in vertebrate chondrogenesis and osteogenesis including collagens FCol1 and FCol2, SPARC, soxE and runx were expressed specifically in the tips of the regenerating skeletal rods. Amphioxus in fact possesses two SPARC genes, conserved since the eumetazoan ancestor, both of which are expressed in the notochord during embryonic development (Bertrand et al., 2013). Combined with expression data in other chordates, this leads the authors to suggest that co-expression of SPARC-like and Collagen proteins in mesenchymal cells was one of the key steps to skeletal evolution (Bertrand et al., 2013). Indeed, a SPARC gene and runx2 are expressed in prospective scleroblast progenitors during scale regeneration in the goldfish, a collagenous dermal skeleton component (limura et al., 2012). It will be interesting to determine whether or not any of these $S P A R C$ and runx genes are expressed during tail regeneration, most specifically in notochord precursors.

Axial regeneration likely occurs via an
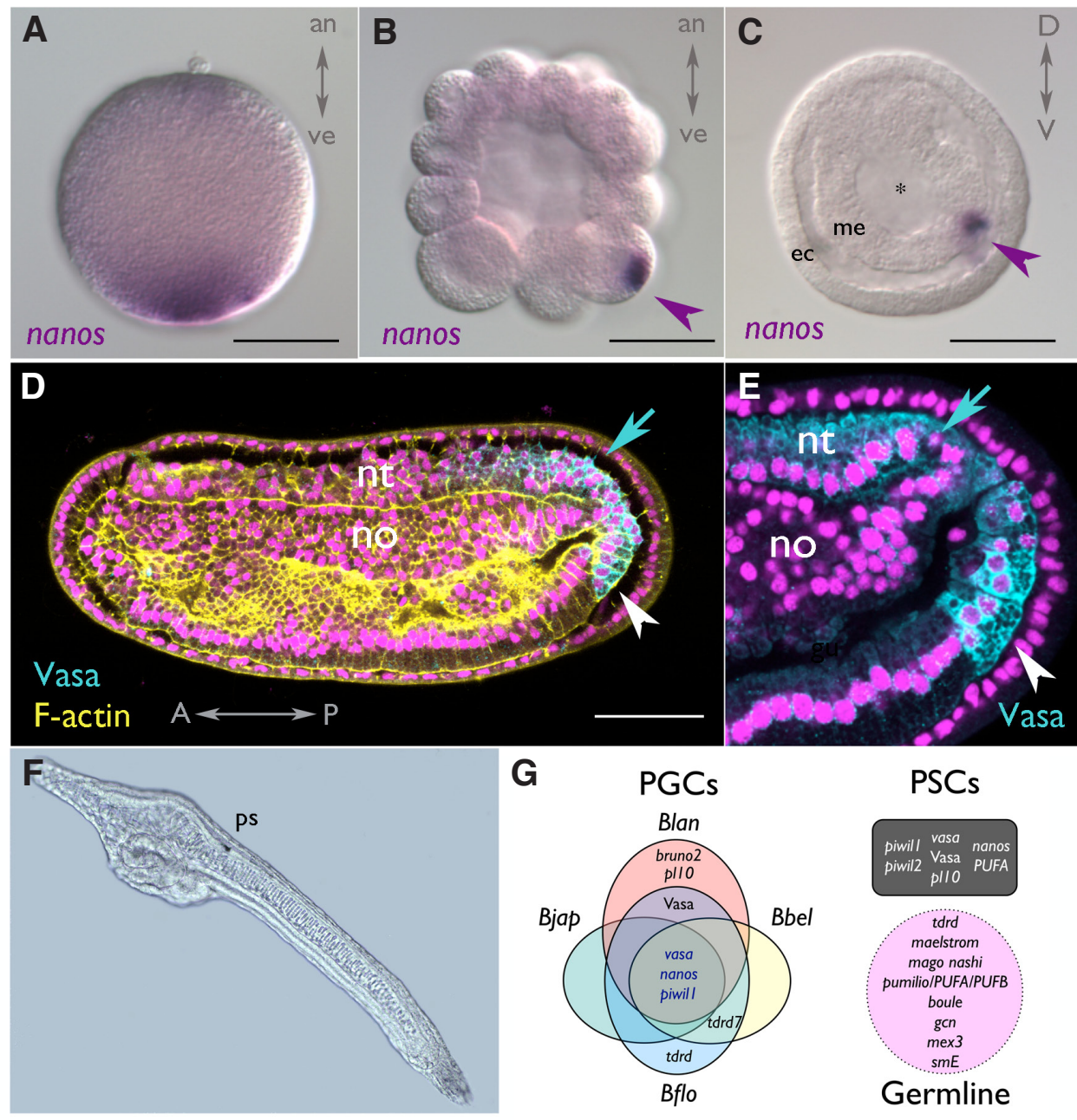

Fig. 3. Evidence for amphioxus stem cell populations. (A-C). nanos transcripts are segregated to the vegetal pole in eggs (A), and inherited by one to a few cells (magenta arrowheads) by PGCs (primitive germ cells) from morula (B) to gastrula (C) stages in cephalochordate embryos (here B. lanceolatum). (D) These cells also express Vasa protein (white arrowheads), as does the posterior neural tube (cyan arrows) at mid-neurula stages [magnification in (E)], as seen by confocal microscopy. (F) Surviving twin of pair of 2-day larvae resulting from dissociation experiment at the 2-cell stage. Note morphological abnormalities in elongation and head/oral structures. (G) Summary of proposed core molecular markers (transcripts and protein) asymmetrically labelling PGCs from studies in four cephalochordate species (Blan: B. lanceolatum; Bbel: B. belcheri; Bjap: B. japonicum; Bflo: B. floridae). A number of these also mark the tailbud, a possible posterior stem cell (PSC) pool (grey box). Other markers may also play a role in the germline based on expression in B. floridae and in silico prediction in A. lucayanum (magenta box). The animal-vegetal (an-ve), Anterior-Posterior (A-P) and Dorso-Ventral $(D-V)$ axes are indicated in each panel where appropriate. Cyan: Vasa; yellow: F-actin; magenta: DAPI labelled nuclei. ec: ectoderm; me: mesendoderm; *: early blastopore; nt: neural tube; no: notochord; ps: pigment spot. Scale, $50 \mu \mathrm{m}$. 
be excluded that progenitors contributing to the regenerate may have migrated from elsewhere, or that there may exist different populations of slow or fast cycling stem cells. BrdU pulse-chase labelling may give additional insight into proliferation kinetics. Altogether, these studies support data in other systems suggesting that proliferation-dependent and -independent mechanisms of regeneration may occur in different tissues in the same organism.

\section{Evidence for amphioxus stem cells}

\section{Primordial germ cells}

Germ cells, by virtue of being able to generate a whole new organism in the next generation, and their close affinity with embryonic stem cells, may be considered stem cells par excellence. In metazoans, two different mechanisms of germline specification have been described: inductive and determined (or "preformation"). In the inductive mechanism, germ cells are specified by signalling, usually relatively late during embryogenesis, while in the determined mode, segregation of germ plasm already in the ooctye determines germ cell fate (Whittle and Extavour 2017).

Although cephalochordates are generally reported as using an inductive mode, recent data in four amphioxus species (all Branchiostoma) suggest rather an inherited mechanism for primordial germ cell (PGC) formation (Wu et al., 2011; Zhang et al., 2013; Dailey et al., 2016). At the two-cell stage, a number of highly conserved germline transcripts including nanos (Fig. 3A-C) and vasa -as well as Vasa protein- are asymmetrically distributed into a single cell, and inherited by few progeny. At the late gastrula stage, up to 8 Vasa+ cells can be identified in B. belcheri (Wu et al., 2011). In neurula stages, these PGCs are nestled posteriorly in endoderm of the tailbud (Fig. 3D, E), and remain as a cluster near the anus in premouth larval stages in all species examined (Wu et al., 2011; Zhang et al., 2013; Dailey et al., 2016).

Given the remarkable conservation of developmental gene expression in Branchiostoma (Somorjai et al., 2008; Yong et al., 2017), comparisons across species, including in silico predictions in Asymmetron lucayanum (Yue et al., 2015) allow a tentative reconstruction of a core set of germline-associated genes in cephalochordates (Fig. 3G). This likely includes nanos, piwil1, vasa, bruno 2 and p/10 and a number of Tudor-related genes, which are asymmetrically localised to the vegetal cortex. However, it may also include PUF-domain containing genes, mago nashior maelstrom, which are more broadly expressed (Yue et al., 2015); these may play roles in germline maintenance or differentiation.

As marker expression is independent of the germline specification mechanism utilised (i.e. nanos, see Fresques et al., 2016), we cannot currently exclude the possibility that other cephalochordate genera utilise non-determinative mechanisms (eg Asymmetron), or that inductive mechanisms may not operate under particular conditions. For instance, removal of PGCs at late stages may permit inductive mechanisms to re-specify germ cells, as seen in the solitary ascidian Ciona intestinalis when the larval tail is amputated (reviewed in Kawamura et al., 2011). However, at least in the earliest cleavage stages, inductive mechanisms do not appear to be operating. Recent blastomere dissociation experiments at the two-cell stage, similar to those performed by Tung (reviewed in Yan 1999), suggest that while morphologically broadly normal twins can be recovered (Wu et al., 2011 and see Fig. 3F), one likely lacks germline as assessed by germ marker expression, and the posterior is malformed (Wu et al., 2011). Taken together, studies of PGC determination in amphioxus such as these will begin to shed light on the nature of stem cell regulation in this taxon.

\section{Somatic progenitors}

Reports in a number of animals suggest that the germ-soma divide is not strict, and that mechanisms used to maintain the PGCs/ germline may also be utilised in somatic stem cells, supporting the existence of an ancestral multipotency programme already in the last common ancestor of metazoans (Juliano et al., 2010; FierroConstain et al., 2017). Thus, many "germline"-associated genes are also expressed in pluripotent somatic progenitors, and can be re-activated during regenerative processes.

In amphioxus, comparative studies suggest the existence of a posterior progenitor/stem cell pool located in the larval tailbud, the growth zone responsible for posterior elongation. Both transcripts and protein of one of the key germline determinants in the PGCs, vasa, localise to this domain, as do nanos and piwil1 and piwil2 (Wu et al., 2011; Zhang et al., 2013; Dailey et al., 2016). Vasa plays a general role in regulating translation in the soma (Poon et al., 2016) and nanos2 has recently been shown to transiently repress translation in PGCs via inhibition of elF1a in sea urchins (Ouhlen et al., 2017). Thus, we might expect expression of such genes in the adult regenerating tail. Indeed, transcriptomic data from the blastema suggest that "germline" genes are in fact acting as general "stemness factors" in amphioxus (Dailey 2017).

While some data exist in adult amphioxus concerning signalling pathways expressed during regeneration (outlined above), the contribution of stem cells to the process is poorly understood due to current technical limitations. A single study in B. lanceolatum has identified a pool of dividing progenitors positive for Pax3/7 in and around the tail blastema, which appear to decline during differentiation and ageing (Somorjai et al., 2012; Fig. 2B). Pax3/7 expressing muscle satellite-like cells with a role in regeneration have also been identified in Parhyale hawaiensis, a crustacean, suggesting that shared mechanisms for muscle regeneration existed in the common ancestor of bilaterians (Konstainides and Averof 2014). However, the contribution of such Pax3/7+ cells to the amphioxus regenerate -and whether or not the mechanisms employed in amphioxus and vertebrates are indeed homologousrequires further study. Recent research in two salamanders, the axololt and the newt, suggests that muscle dedifferentiation and satellite cell contributions may differ across species (SandovalGuzman et al., 2014). However, the differences observed between the two could also reflect changes in cellular mechanisms and resident stem cell activation during ontogeny (Tanaka et al., 2016). Either way, these have important implications: the first suggests the evolution of an alternate strategy to achieve the same regenerative outcome within urodeles, while the latter has a clear impact on our approach to regenerative medicine. Understanding how amphioxus regenerates muscle may help polarise our views on ancestral mechanisms in chordates.

\section{Outlook}

Regeneration and stem cell research in cephalochordates are still at an embryonic stage. We know next to nothing about how different resident progenitor populations contribute to the new regenerate or the cellular mechanisms involved. However, an 
understanding of how amphioxus fits into the broader spectrum of animal regeneration generally, and chordate and vertebrate regeneration more specifically, contributes to our understanding of the diversity of mechanisms utilised by animals to repair injuries and replace lost tissues. This in turn has potential biomedical implications: the blastema is effectively a tumour, but undergoing controlled growth, differentiation and patterning. Insight gained into how complex tissue regeneration is regulated in adult amphioxus, and how this potential declines with age, may help inform us about degenerative disease and ageing-associated stem cell misregulation in humans.

Based on studies in other chordates, one can make a number of predictions about amphioxus tail regeneration. As demonstrated in amphibians (Gargioli and Slack 2004; Kragl et al., 2009), notochord, muscle and nerve cord lineages are likely defined early in amphioxus, with little to no lineage switching. However, additional distant sources of progenitors may also contribute to the tail blastema in cephalochordates. For instance, branchial sac stem cells in the solitary ascidian Ciona intestinalis contribute to distal regeneration (Jeffery 2015). Moreover, in some colonial ascidians, small pieces of vessel containing blood cells are sufficient to regenerate an entire organism (Rinkevich et al., 1995), and the endostyle, homologue of the vertebrate thyroid gland, acts as a stem cell niche (Voskoboynik et al., 2008). Although circulating cells are lacking in cephalochordates, amphioxus blood vessels do contain coelomocytes or amoebocytes with some migratory and endocytic capabilities (Rhodes et al., 1982; Monahan-Earley et al., 2013). Further, amphioxus have a well-developed endostyle within the floor of the branchial basket, which could act as a niche due to its close apposition to the circulatory system there, in addition to more local signals originating from the wound epithelium to the underlying tail blastemal cells. The embryonic tailbud is a source of numerous signals in amphioxus (i.e. Wnt, BMP etc.; Bertrand et al., in press) that might regulate proliferation/differentiation of the posterior stem cell pool, similarly to what occurs during posterior regenerate outgrowth. Regeneration and developmental research in amphioxus will therefore have to progress side-by-side within a comparative framework; highlighting differences is as important as identifying commonalities among systems. Ultimately, research in amphioxus, an invertebrate with conserved chordate anatomy and simpler genome, provides an attractive foil and complement to regeneration and stem cell studies in vertebrates.

\section{Acknowledgements}

I would like to thank Nicholas Holland for 10 o'clock espresso breaks at the kiosk, Russian translations, and fine wine; Linda Holland for tips on amphioxus care and numerous suppers; and reviewers for constructive criticism that improved the manuscript. Experimental work in my lab is currently funded by the Wellcome Trust ISSF grant 204821/Z/16/Z, the European Union Horizon 2020 research and innovation programme under grant agreement numbers 654428 ("CORBEL") and 730984("ASSEMBLE+) and the RS MacDonald Charitable Trust. I apologise to the many authors whose primary literature could not be cited due to space restrictions.

\section{References}

ANDREWS EA (1893). An undescribed acraniate, Asymmetron lucayanum. Stud Biol Lab Johns Hopkins Univ 5: 213-247.

BELY AE and NYBERG KG (2010). Evolution of animal regeneration: re-emergence of a field. Trends Ecol Evol 25: 161-170.
BERT MP (1867). On the anatomy and physiology of amphioxus. Annals Mag. Nat. Hist. 20: 302-304.

BERTRANDS, LE PETILLONY, SOMORJAII, and ESCRIVAE (2017). Developmenta cell-cell communication pathways in the cephalochordate amphioxus: actors and functions (doi: 10.1387/ijdb.170202sb)

BERTRAND S, FUENTEALBA J, AZE A, HUDSON C, YASUO H, TORREJON M, ESCRIVA $H$ and MARCELLINI S (2013). A dynamic history of gene duplications and losses characterizes the evolution of the SPARC family in eumetazoans. Proc Biol Sci 280: 20122963.

BIBERHOFER R. (1906) Über Regeneration bei Amphioxus lanceolatus (1906). Arch EntwMech Org 22: 15-17.

BONE Q (1992). Protochordates. J Mar Biol Assoc UK 72: 952-953.

BROCKES JP and KUMAR A (2008). Comparative aspects of animal regeneration. Annu Rev Cell Dev Biol 24: 525-549.

CARNEVALI MD (2006). Regeneration in echinoderms: repair, regrowth, cloning. Invertebrate Surviv J 3: 64-76

CZARKWIANIA, FERRARIO C, DYLUSDV, SUGNIM and OLIVERIP(2016). Skeletal regeneration in the brittle star Amphiura filiformis. Front Zool 13: 18.

DAILEY SC, FEBRERO PLANAS R, ROSSELL ESPIER A, GARCIA-FERNANDEZ $J$ and SOMORJAI I (2016). Asymmetric distribution of pl10 and bruno2, new members of a conserved core of early germline determinants in cephalochordates. Front Ecol Evol 3: 156

DAILEY SC (2017). Evolutionary developmental and genomic insights from a tail regeneration transcriptome of the cephalochordate Branchiostoma lanceolatum. PhD Thesis. University of St Andrews, Scotland, UK.

DAILEY SC, KOZMIKOVA I, SOMORJAI I (2017). Amphioxus Sp5 is a member of a conserved Specificity Protein complement and is modulated by Wnt/b-catenin signalling (doi: 10.1387/ijdb.170205sb).

FENG J, LI G, LIU X, WANG J, and WANG YQ (2014). Functional analysis of the promoter region of amphioxus $\beta$-actin gene: a useful tool for driving gene expression in vivo. Mol Biol Rep 41: 6817-6826.

FIERRO-CONSTAÍN L, SCHENKELAARSQ, GAZAVEE, HAGUENAUERA, ROCHER C,ERESKOVSKYA, BORCHIELINIC, RENARDE (2017). The conservation of the germline multipotency program, from sponges to vertebrates: A stepping stone to understanding the somatic and germline origins. Genome Biol Evol 9: 474-488.

FRANZ V (1925). Morphologische und ontogenetische Akranierstudien über Darm, Trichter, Zölomderivate, Muskulatur- und Bindegewebsformationen. Jenaische Zeitschrift für Naturwissenschaft 61: 407-468.

FRESQUES T, SWARTZ SZ, JULIANO C, MORINO Y, KIKUCHI M, AKASAKA K, WADA H, YAJIMA M and WESSEL GM (2016). The diversity of nanos expression in echinoderm embryos supports different mechanisms in germ cell specification. Evol Dev 18: 267-278.

GAWRILUK TR, SIMKIN J, THOMPSON KL, BISWAS SK, CLARE-SALZLER Z, KIMANI JM, KIAMA SG, SMITH JJ, EZENWA VO and SEIFERT AW (2016). Comparative analysis of ear-hole closure identifies epimorphic regeneration as a discrete trait in mammals. Nat Commun 7: 11164.

GARGIOLI C and SLACK JM (2004). Cell lineage tracing during Xenopus tail regeneration. Development 131: 2669-2679.

GEMBERLING M, BAILEY TJ, HYDE DR and POSS KD (2013). The zebrafish as a model for complex tissue regeneration. Trends Genet 29: 611-620.

HAAS BJ and WHITED JL (2017). Advances in decoding axolotl limb regeneration. Trends Genet 33: 553-565.

HENRY JJ and TSONIS PA (2010). Molecular and cellular aspects of amphibian lens regeneration. Prog Retin Eye Res 29: 543-555.

IIMURAK, TOHSE H, URAK, and TAKAGAKIY (2012). Expression patterns of runx2, sparc, and bgp during scale regeneration in the goldfish Carassius auratus. J Exp Zool B Mol Dev Evol 318: 190-198.

IGAWA T, NOZAWA M, SUZUKI DG, REIMER JD, MOROV AR, WANG Y, HENMI Y and YASUI K (2017). Evolutionary history of the extant amphioxus lineage with shallow-branching diversification. Sci Rep 7: 1157.

JEFFERY WR (2015). Distal regeneration involves the age dependent activity of branchial sac stem cells in the ascidian Ciona intestinalis. Regeneration (Oxf) 2: 1-18.

JULIANO CE, SWARTZ SZ and WESSEL GM (2010). A conserved germline multipotency program. Development 137: 4113-4126. 
KANETO S and WADA H (2011). Regeneration of amphioxus oral cirri and its skeletal rods: implications for the origin of the vertebrate skeleton. J Exp Zool B Mol Dev Evol 316: 409-417.

KAWAMURAK, TIOZZOS, MANNI L, SUNANAGAT, BURIGHELP, and DE TOMASO AW (2011). Germline cell formation and gonad regeneration in solitary and colonial ascidians. Dev Dyn 240: 299-308.

KONSTANTINIDES N and AVEROF M (2014). A common cellular basis for muscle regeneration in arthropods and vertebrates. Science 343: 788-791.

KOZMIKOVA I and KOZMIK Z (2015). Gene regulation in amphioxus: An insight from transgenic studies in amphioxus and vertebrates. Mar Genomics 24 Pt 2: 159-166.

KRAGL M, KNAPP D, NACU E, KHATTAK S, MADEN M, EPPERLEIN HH and TANAKA EM (2009). Cells keep a memory of their tissue origin during axolotl limb regeneration. Nature 460: 60-65

KÜRN U, RENDULIC S, TIOZZO S and Lauzon RJ (2011). Asexual propagation and regeneration in colonial ascidians. Biol Bull 221: 43-61.

LEHOCZKY JA, ROBERTB and TABIN CJ (2011). Mouse digit tip regeneration is mediated by fate-restricted progenitor cells. Proc NatIAcad Sci USA 108: 20609-20614.

MONAHAN-EARLEY R, DVORAK AM and AIRD WC (2013). Evolutionary origins of the blood vascular system and endothelium. J Thromb Haemost 11 Suppl 1: 46-66.

NOGUEIRAAF, COSTACM, LORENAJ, MOREIRARN, FROTA-LIMAGN, FURTADO C, ROBINSON M, AMEMIYACT, DARNET S and SCHNEIDER I (2016). Tetrapod limb and sarcopterygian fin regeneration share a core genetic programme. Nat Commun 7: 13364.

NUSBAUM J (1905). Vergleichende Regenerationsstudien. Ueber die Regeneration der Polychäten Amphiglene mediterranea Leydig und Nerine cirratulus Delle Chiaje. Z Wiss Zool 79: 222-307

OULHEN N, SWARTZSZ, LAIRD J, MASCAROA and WESSEL GM (2017). Transient translational quiescence in primordial germ cells. Development 144: 1201-1210.

OULION S, BERTRAND S, BELGACEM MR, LE PETILLON Y and ESCRIVA H (2012). Sequencing and analysis of the Mediterranean amphioxus (Branchiostoma lanceolatum) transcriptome. PLoS One 7:e36554.

PEGETAVP (1992) The regenerative capacity of the tail section of the cephalochordate (in Russian). Vestn Zool [Zoological Herald] (Kiev) 1: 74-76.

POON J, WESSEL GM and YAJIMAM (2016). An unregulated regulator: Vasa expression in the development of somatic cells and in tumorigenesis. Dev Biol415:24-32.

POSS SG and BOSCHUNG HT (1996). Lancelets (Cephalochordata: Branchiostomatidae): how many species are valid? Israel J Zool 42: Suppl 13-66.

PROBST G (1930). Regenerationsstudien an Anneliden und Branchiostoma lanceolatum (Pallas). Rev Suisse Zool 37: 343-352.

PUTNAM NH, BUTTST, FERRIERDE, FURLONG RF, HELLSTENU, KAWASHIMAT, ROBINSON-RECHAVIM, SHOGUCHIE, TERRYA, YUJK, BENITO-GUTIÉRREZ EL, DUBCHAK I, GARCIA-FERNÀNDEZ J, GIBSON-BROWN JJ, GRIGORIEV IV, HORTON AC, DE JONG PJ, JURKAJ, KAPITONOV VV, KOHARAY, KUROKI Y, LINDQUIST E, LUCAS S, OSOEGAWA K, PENNACCHIO LA, SALAMOV AA, SATOU Y, SAUKA-SPENGLER T, SCHMUTZ J, SHIN-I T, TOYODA A, BRONNER-FRASER M, FUJIYAMA A, HOLLAND LZ, HOLLAND PW, SATOH $\mathrm{N}$, and ROKHSAR DS (2008). The amphioxus genome and the evolution of the chordate karyotype. Nature 453: 1064-1071.

RHODES CP, RATCLIFFE NA and ROWLEY AF (1982). Presence of coelomocytes in the primitive chordate amphioxus (Branchiostoma lanceolatum). Science 217: 263-265.

RINKEVICHB, SHLEMBERG Z and FISHELSON L (1995). Whole-body protochordate regeneration from totipotent blood cells. Proc Natl Acad Sci USA 92: 7695-7699.

RINKEVICH Y, LINDAU P, UENO H, LONGAKER MT and WEISSMAN IL (2011). Germ-layer and lineage-restricted stem/progenitors regenerate the mouse digit tip. Nature 476: 409-413.

SANDOVAL-GUZMÁNT, WANG H, KHATTAKS, SCHUEZM, ROENSCHK, NACUE, TAZAKIA, JOVENA, TANAKAEM and SIMONA(2014). Fundamental differences in dedifferentiation and stem cell recruitment during skeletal muscle regeneration in two salamander species. Cell Stem Cell 14: 174-187.

SEIFERT AW, KIAMA SG, SEIFERT MG, GOHEEN JR, PALMER TM and MADEN $M$ (2012). Skin shedding and tissue regeneration in African spiny mice (Acomys).
Nature 489: 561-565.

SEIFERT AW and VOSS SR (2013). Revisiting the relationship between regenerative ability and aging. BMC Biol 11: 2 .

SILVA JR, MENDES EG and MARIANO M (1995). Wound repair in the Amphioxus (Branchiostoma platae), an animal deprived of inflammatory phagocytes. J Invertebr Pathol 65: 147-151.

SILVAJRMC, MENDES EG and MARIANO M (1998). Regeneration in the amphioxus (Branchiostoma platae). Zoologischer Anzeiger 237: 107-112.

SLACK JM (2017). Animal regeneration: ancestral character or evolutionary novelty? EMBO Rep pii: e201643795.

SOMORJAI I, BERTRAND S, CAMASSES A, HAGUENAUER A and ESCRIVA H (2008). Evidence for stasis and not genetic piracy in developmental expression patterns of Branchiostoma lanceolatum and Branchiostoma floridae, two amphioxus species that have evolved independently over the course of $200 \mathrm{Myr}$. Dev Genes Evol 218(11-12): 703-713.

SOMORJAI IML, SOMORJAI RL, GARCIA-FERNÀNDEZJ and ESCRIVÀ H (2012a). Vertebrate-like regeneration in the invertebrate chordate amphioxus. Proc Natl Acad Sci USA 109: 517-522.

SOMORJAI IML, ESCRIVÀ H and GARCIA-FERNÀNDEZ J (2012b). Amphioxus makes the cut-Again. Commun Integr Biol 5: 499-502.

TANAKA HV, NG NC, YANG YU Z, CASCO-ROBLES MM, MARUO F, TSONIS PA and CHIBA C (2016). A developmentally regulated switch from stem cells to dedifferentiation for limb muscle regeneration in newts. Nat Commun 7: 11069.

UNGUEZ GA (2013). Electric fish: new insights into conserved processes of adult tissue regeneration. J Exp Biol 216: 2478-2486.

VORONTSOVA MA and LIOSNER LD (Eds.) (1960). Asexual Propagation and Regeneration. Pergamon, Oxford.

VOSKOBOYNIK A, SOEN Y, RINKEVICH Y, ROSNER A, UENO H, RESHEF R, ISHIZUKA KJ, PALMERI KJ, MOISEEVA E, RINKEVICH B and WEISSMAN IL (2008). Identification of the endostyle as a stem cell niche in a colonial chordate. Cell Stem Cell 3: 456-464.

VOSS GJ, KUMP DK, WALKER JA and VOSS SR (2013). Variation in salamander tail regeneration is associated with genetic factors that determine tail morphology. PLoS One 8:e67274

WANG YB, CHEN SH, LIN CY and YU JK (2012). EST and transcriptome analysis of cephalochordate amphioxus-past, present and future. Brief Funct Genomics 11: 96-106.

WHITTLE CA and EXTAVOUR CG (2017). Causes and evolutionary consequences of primordial germ-cell specification mode in metazoans. Proc Natl Acad Sci USA 114: 5784-5791.

WU HR, CHEN YT, SU YH, LUO YJ, HOLLAND LZ and Yu JK (2011). Asymmetric localization of germline markers Vasa and Nanos during early development in the amphioxus Branchiostoma floridae. Dev Biol 353: 147-159.

YAJIMA M and WESSEL GM (2015). Essential elements for translation: the germline factor Vasa functions broadly in somatic cells. Development 142, 1960-1970.

YONG LW, BERTRAND S, YU JK, ESCRIVAH and HOLLAND ND (2017). Conservation of BMP2/4 expression patterns within the clade Branchiostoma (amphioxus): Resolving interspecific discrepancies. Gene Expr Patterns 25-26: 71-75.

YUE JX, YU JK, PUTNAM NH and HOLLAND LZ (2014). The transcriptome of an amphioxus, Asymmetron lucayanum, from the Bahamas: a window into chordate evolution. Genome Biol Evol 6: 2681-2696.

YUE JX, LI KL and YU JK (2015). Discovery of germline-related genes in Cephalochordate amphioxus: A genome wide survey using genome annotation and transcriptome data. Mar Genomics 24: 147-157.

YUE JX, KOZMIKOVA I, ONO H, NOSSA CW, KOZMIK Z, PUTNAM NH, YU JK, and HOLLAND LZ (2016). Conserved noncoding elements in the most distant genera of cephalochordates: the Goldilocks principle. Genome Biol Evol 8: 2387-2405.

ZHANG QJ, LUO YJ, WU HR, CHEN YT and Yu JK (2013). Expression of germline markers in three species of amphioxus supports a preformation mechanism of germ cell development in cephalochordates. EvoDevo 4: 17.

ZHANG Q, LI G, SUN Y and WANG Y (2009). Chromosome preparation and preliminary observation of two amphioxus species in Xiamen. Zool Res 30: 131-136. 


\section{Further Related Reading, published previously in the Int. J. Dev. Biol.}

Planaria: an animal model that integrates development, regeneration and pharmacology Oné R. Pagán

Int. J. Dev. Biol. (2017) 61: 519-529

Reptile genomes open the frontier for comparative analysis of amniote development and regeneration Marc Tollis, Elizabeth D. Hutchins and Kenro Kusumi

Int. J. Dev. Biol. (2014) 58: 863-871

Regeneration in spiralians: evolutionary patterns and developmental processes Alexandra E. Bely, Eduardo E. Zattara and James M. Sikes

Int. J. Dev. Biol. (2014) 58: 623-634

From the American to the European amphioxus: towards experimental Evo-Devo at the origin of chordates

Jordi Garcia-Fernàndez, Senda Jiménez-Delgado, Juan Pascual-Anaya, Ignacio Maeso, Manuel Irimia, Carolina Minguillón, Ėlia Benito-Gutiérrez, Josep Gardenyes, Stéphanie Bertrand and Salvatore D'Aniello

Int. J. Dev. Biol. (2009) 53: 1359-1366

https://doi.org/10.1387/ijdb.072436jg

The germ line and somatic stem cell gene Cniwi in the jellyfish Podocoryne carnea. Katja Seipel, Nathalie Yanze and Volker Schmid Int. J. Dev. Biol. (2004) 48: 1-7

FGF signalling and blastema growth during amphibian tail regeneration P Ferretti, F Zhang, L Santos-Ruiz, JDW Clarke Int. J. Dev. Biol. (2001) 45: S127-S128

5 yr ISI Impact Factor $(2013)=2.879$
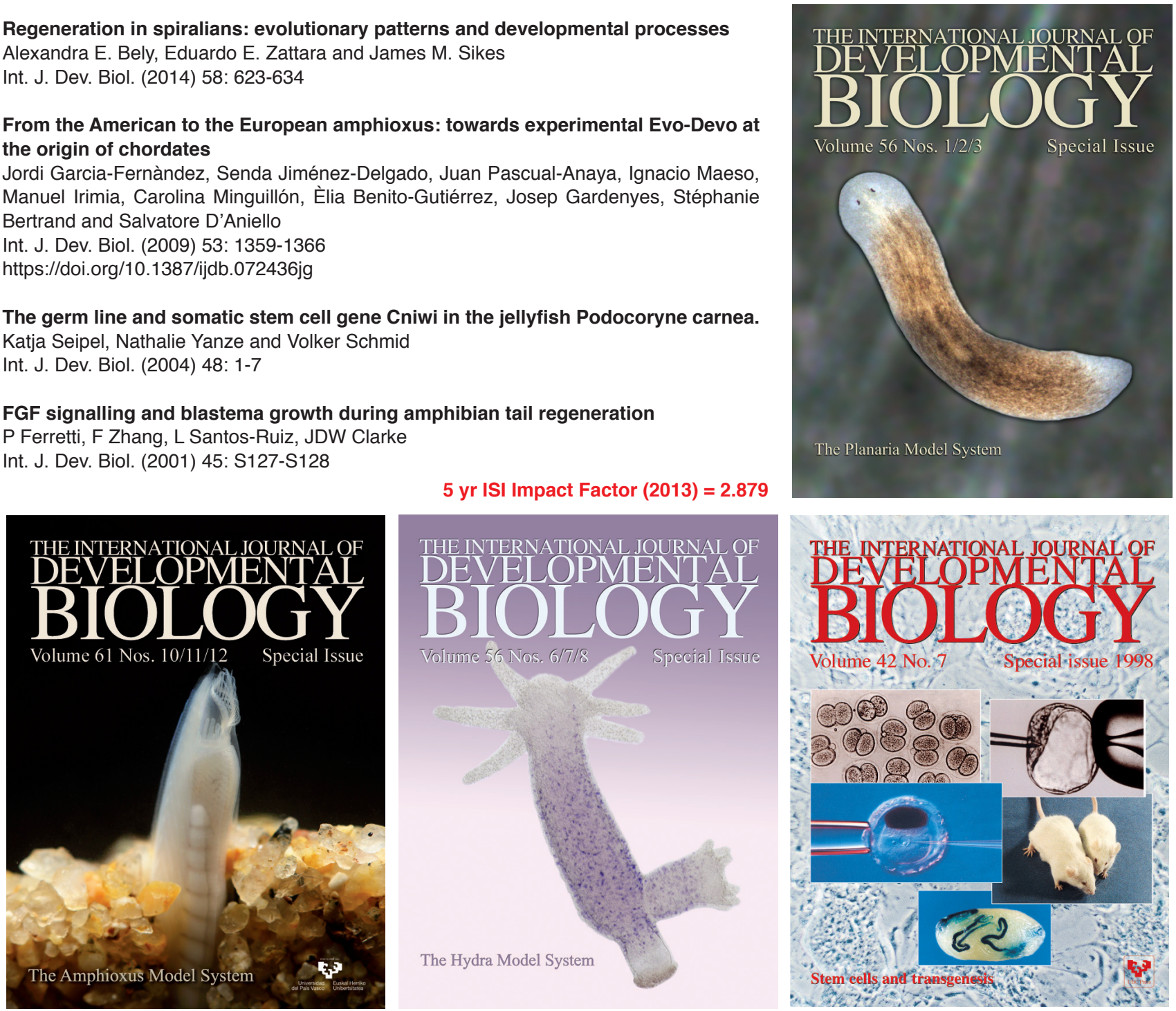